\title{
Interactions between Phosphoric/Tannic Acid and Different Forms of FeOOH
}

\author{
Lefu Mei, ${ }^{1}$ Libing Liao, ${ }^{1}$ Zise Wang, ${ }^{2}$ and Chunchun $\mathrm{Xu}^{3}$ \\ ${ }^{1}$ School of Material Sciences and Technology, China University of Geosciences, Beijing 100083, China \\ ${ }^{2}$ China Science and Technology Museum, Beijing 100029, China \\ ${ }^{3}$ School of Material Sciences and Technology, Beijing University of Chemical Technology, Beijing 100029, China
}

Correspondence should be addressed to Lefu Mei; mlf@cugb.edu.cn and Libing Liao; clayl@cugb.edu.cn

Received 23 July 2014; Accepted 17 September 2014

Academic Editor: Zhaohui Li

Copyright (C) 2015 Lefu Mei et al. This is an open access article distributed under the Creative Commons Attribution License, which permits unrestricted use, distribution, and reproduction in any medium, provided the original work is properly cited.

\begin{abstract}
Alpha, beta, gamma, and delta hydroxyl ferric oxides (FeOOH), as the most common rust layers on iron surface, play different roles in iron preservation. Using modern surface analysis technologies such as X-ray diffraction (XRD), infrared spectra (IR), Xray photoelectron spectroscopy (XPS), and scanning electron microscopy (SEM), we studied the interactions between these four types of synthetic FeOOH and phosphoric and tannic acid of different concentrations and proportions. A 3\% tannic acid $+10 \%$ phosphoric acid $+\mathrm{FeOOH}$ was the most suitable formula for rust stabilizer and its reaction products were made up of iron phosphate and chelate of iron and tannin. This research provided technical basis in distinguishing $\mathrm{FeOOH}$ and selecting rust layer stabilizer for the preservation of iron, especially iron cultural relics.
\end{abstract}

\section{Introduction}

Structure and composition of corrosion products on iron are two important factors of causing its further corrosion, apart from environmental factors, iron components, and defect and inclusion in iron. There are two types of rust layers: a loose outer rust layer and a dense inner rust layer. The former was composed of $\alpha$-FeOOH, $\gamma$ - $\mathrm{FeOOH}$, magnetite $\left(\mathrm{Fe}_{3} \mathrm{O}_{4}\right), \mathrm{H}_{2} \mathrm{O}$, and amorphous ferric oxyhydroxide $\left(\mathrm{FeO}_{x}(\mathrm{OH})_{3-2 x}, x=0-1\right)$, while the latter was composed mainly of $\mathrm{Fe}_{3} \mathrm{O}_{4}$ with a little $\alpha$-FeOOH $[1,2]$. The $\beta$-FeOOH is a typical product of $\mathrm{FeCl}_{3}$ hydrolysis, whereas $\alpha$-FeOOH is that of $\mathrm{Fe}\left(\mathrm{NO}_{3}\right)_{3}$ hydrolysis and under specific conditions these hydrolytic products may transform to $\alpha-\mathrm{Fe}_{2} \mathrm{O}_{3}$ [3-5]. The $\delta$ - $\mathrm{FeOOH}$ is a type of amorphous hydroxyl oxide rust layer on iron material surface [6], forming a compact rust layer that enhances corrosion resistance of the steel [7].

The underlying corrosion of carbon steel was dependent on the inherent properties of the rust layers formed under different conditions such as composition and structure with $\beta$-FeOOH exerting significant influence among all the iron oxides [8]. In terms of reaction with $\mathrm{Fe}(\mathrm{OH})_{2}$ to produce
$\mathrm{Fe}_{3} \mathrm{O}_{4}$, the following order was observed: $\beta$-FeOOH $>\alpha$ $\mathrm{FeOOH} \gg \gamma$-FeOOH [9].

Rust converters are chemical formulations that can be applied to corroded surfaces causing their passivation and elimination of possible further attack after the application of a coating [10]. To reduce the effects of hydroxyl ferric oxide on steel preservation, surface stabilizing treatment of rust layer has been widely used in the steel anticorrosion field. By employing a processing method of a chemical conversion film, the hydroxyl oxide rust layer on the iron may undertake a chemical conversion and form porous membrane barrier with good ventilation property and water permeability [11]. The excellent atmospheric corrosion resistance of the phosphoric Dhar pillar iron was attributed to the formation of a protective passive film on the surface [12]. Chemical conversion film, as inoxidizing coating of metal, reduces chemical activity of the metal and increases thermodynamic stability of steel in environmental medium. In addition, the surface products may also play a certain role in metal isolation from environmental medium. Chemical conversion films such as thin layer, exquisite crystallization, and porosity, may be combined with sealing materials. Accordingly, industrial 
anticorrosion methods provide research foundation for surface stabilizing treatment of iron relics.

The chromate salt passivation treatment method [13] is an effective chemical conversion technology. In spite of a good corrosion prevention effect, its use is limited by environmental regulations, due to high toxicity and carcinogenicity of hexavalent chromium [14-16].

Phosphate covering by forming a phosphate film on metals using phosphoric acid or zinc phosphate, manganese phosphate, or iron phosphate solution possesses many advantages, such as anticorrosion, wear-resisting, antifriction, increasing lubricity, and promoting base adhesion between coating and metal [17]. Phosphorus processing, therefore, is widely applied in processing steel parts, especially coating layer process [18]. Separately, pretreatment of reinforced steel surface with tannic acid based rust converter prior to the application of zinc rich coating improved the corrosion resistance appreciably $[19,20]$.

As one of metal surface treatment methods, tannins have potential application prospects, with low toxicity, low pollution, low usage volume, and even color with excellent corrosion-resistant performance [21]. Tannins as corrosion inhibitors were applied both in solvent and waterborne pretreatment formulations [22]. These formulations could be applied on partially rusted substrates, reducing the effort needed for cleaning the surface by methods which proved to be expensive and are not applicable in many situations [21]. Thus, combination of phosphoric acid and tannic acid may provide a synergistic effect on corrosion resistance of iron cultural relics.

In this study, X-ray diffraction (XRD), infrared spectroscopy (IR), X-ray photoelectron spectrometry (XPS), and transmission electron microscopy (TEM) were used to characterize the four types of $\mathrm{FeOOH}$, as well as to investigate the interactions between $\mathrm{FeOOH}$ and mixed solutions containing different concentrations and proportions of phosphoric acid and tannic acid in order to provide technical basis to distinguish these types of $\mathrm{FeOOH}$ and enable rust layer stabilizer selection for preservation of steel, especially for iron cultural relics.

\section{Experimental Details}

2.1. Preparation of $\alpha$-, $\beta$-, $\gamma$-, and $\delta$-FeOOH. Rust analyses revealed the presence of crystalline magnetite $\left(\mathrm{Fe}_{3-x} \mathrm{O}_{4}\right), \alpha$ $\mathrm{Fe}_{2} \mathrm{O}_{3}$ (haematite), goethite $(\alpha-\mathrm{FeOOH})$, lepidocrocite $(\gamma$ $\mathrm{FeOOH})$, akaganeite $(\beta-\mathrm{FeOOH})$, and amorphous $\delta$-FeOOH phases [12]. Thus, the four $\mathrm{FeOOH}$ polymorphs were prepared to investigate their effects on iron rust.

The $\alpha$-FeOOH was prepared using a solution containing $40 \mathrm{~g}$ of $\mathrm{FeSO}_{4}$ and $8 \mathrm{~g}$ of $\mathrm{NaOH}$ per liter of deionized (DI) water. The temperature was adjusted to $50^{\circ} \mathrm{C}$ and $\mathrm{pH}$ to 13 with $10 \mathrm{wt} \% \mathrm{NaOH}$. The solution was fluxed with oxygen for $8 \mathrm{~h}$. The precipitates were washed with 10 portions of DI water until the filtrate became neutral in $\mathrm{pH}$ before being dried at $100^{\circ} \mathrm{C}$.

The $\gamma$-FeOOH was prepared using a solution made of $60 \mathrm{~g}$ of $\mathrm{FeCl}_{2} \cdot 4 \mathrm{H}_{2} \mathrm{O}$ in $1 \mathrm{~L}$ of DI water. Meanwhile, $84 \mathrm{~g}$ of urotropine and $21 \mathrm{~g}$ of $\mathrm{NaNO}_{2}$ each were dissolved in $300 \mathrm{~mL}$ of DI water. After the $\mathrm{FeCl}_{2} \cdot 4 \mathrm{H}_{2} \mathrm{O}$ solution was mixed with urotropine solution, $\mathrm{NaNO}_{2}$ was added into the mixture under constant stir at room temperature. The mixture was heated to $60^{\circ} \mathrm{C}$ under constant stir for $3 \mathrm{~h}$. The precipitates were washed with hot water and dried at $60^{\circ} \mathrm{C}$.

The $\beta$-FeOOH was prepared using a $0.2 \mathrm{M} \mathrm{FeCl}_{3}$ solution heated to $60^{\circ} \mathrm{C}$ for $5 \mathrm{~h}$. Then, small quantities of $3.175 \mathrm{mM}$ EDTA and ammonia were added. The precipitates were washed with DI water until no $\mathrm{Cl}^{-}$was detected before being dried at $70^{\circ} \mathrm{C}$ for $24 \mathrm{~h}$.

The $\delta$-FeOOH was prepared using a solution made of $40 \mathrm{~g}$ $\mathrm{FeSO}_{4}$ and $8 \mathrm{~g} \mathrm{NaOH}$ per liter of DI water. A $10 \mathrm{wt} \% \mathrm{NaOH}$ solution was added dropwise till abundant brown precipitates were formed at room temperature. Then, small quantities of EDTA were added before the precipitates were filtered out.

2.2. Test on the Influence of $\beta-\mathrm{FeOOH}$ and $\gamma-\mathrm{FeOOH}$ on Iron Rusting. Archaize iron was used as the experimental material. It had a composition of (wt $\%) 4.17 \% \mathrm{C}, 0.59 \% \mathrm{Si}$, $0.32 \% \mathrm{Mn}, 0.087 \% \mathrm{~S}$, and $0.017 \% \mathrm{P}$. The samples were cut into coupons each with a dimension of $15 \mathrm{~mm} \times 15 \mathrm{~mm} \times$ $3 \mathrm{~mm}$. A corrosion cell with a dimension of $10 \mathrm{~mm} \times$ $10 \mathrm{~mm} \times 0.5 \mathrm{~mm}$ was cut in the middle (Figure 1). One $\mathrm{g}$ synthetic $\beta$-FeOOH powder and one g synthetic $\gamma$ $\mathrm{FeOOH}$ powder were added into separate cells. The $\mathrm{FeOOH}$ powder was pressed with a glass slide. A drop of each of the following corrosion media was added to the corresponding cell each day Monday through Friday for 10 months: $0.01 \mathrm{~mol} / \mathrm{L} \mathrm{NO}_{3}{ }^{-}, 0.01 \mathrm{~mol} / \mathrm{L} \mathrm{Cl}^{-}, 0.01 \mathrm{~mol} / \mathrm{L} \mathrm{HSO}_{4}{ }^{-}$, and $0.01 \mathrm{~mol} / \mathrm{L} \mathrm{Cl}^{-}+0.01 \mathrm{~mol} / \mathrm{L} \mathrm{HSO}_{4}{ }^{-}$. At the end of the experiment the specimens were encapsulated into epoxy resin. The resin was carefully ground till the rust layer and iron clearly appeared. Observation of propagation of rust under the influence of $\mathrm{NO}_{3}{ }^{-}, \mathrm{Cl}^{-}, \mathrm{HSO}_{4}{ }^{-}$, and $\mathrm{Cl}^{-}+\mathrm{HSO}_{4}{ }^{-}$ was made using scanning electron microscope (SEM).

2.3. Interactions between FeOOH and Phosphoric Acid/Tannic Acid. To each test tube, $2 \mathrm{~g}$ of $\beta$-FeOOH, $\gamma$-FeOOH, or $\delta$ FeOOH was added. Then, $20 \mathrm{~mL}$ of tannic acid + phosphoric acid solution of different concentrations was added (Table 1). The tubes were sealed and shaken for varying amounts of time and then were allowed left aside for a while to ensure complete reaction inside. At the end of reaction, the products were filtered, washed with DI water repeatedly, and dried at $50^{\circ} \mathrm{C}$.

2.4. Characterization of $\mathrm{FeOOH}$. Phase identification was conducted using an XRD-6000 X-ray diffractometer (Shimadzu, Japan) with a CuK $\alpha$ radiation $(\lambda=1.5418 \AA)$ at $40 \mathrm{kV}$ and $30 \mathrm{~mA}$, a scanning speed of $5^{\circ} / \mathrm{min}$, and a scan range of $3-90^{\circ}$. FTIR spectra were acquired on a Bruker VECTOR 22 infrared spectrometer at a resolution of $2 \mathrm{~cm}^{-1}$ and a scan range of $4000-400 \mathrm{~cm}^{-1}$ with a $\mathrm{KBr}$ pressing method. The morphology of FeOOH was characterized by a TEM. Power samples were added to anhydrous ethanol and ultrasonicated for 30 minutes. A little drip of suspension was put onto a copper mesh and dried naturally before TEM observation. 


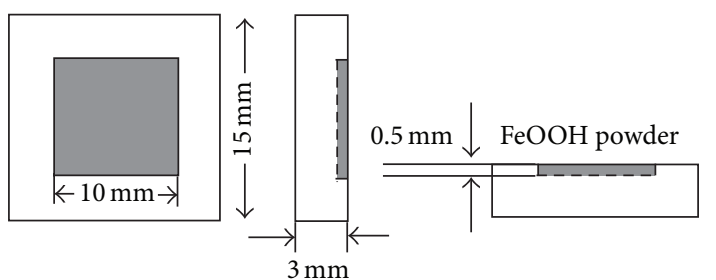

FIGURE 1: Test device for the study of iron corrosion in the presence of different types of $\mathrm{FeOOH}$.

TABLE 1: The combinations of tannic acid/phosphoric acid (wt\%).

\begin{tabular}{lcc}
\hline Number & Tannic acid/phosphoric acid & Labeling \\
\hline 1 & $3 \%$ tannic acid $+10 \%$ phosphoric acid & 3T-10P \\
2 & $3 \%$ tannic acid $+20 \%$ phosphoric acid & $3 \mathrm{~T}-20 \mathrm{P}$ \\
3 & $3 \%$ tannic acid $+30 \%$ phosphoric acid & $3 \mathrm{~T}-30 \mathrm{P}$ \\
4 & $5 \%$ tannic acid $+10 \%$ phosphoric acid & $5 \mathrm{~T}-10 \mathrm{P}$ \\
5 & $5 \%$ tannic acid $+20 \%$ phosphoric acid & $5 \mathrm{~T}-20 \mathrm{P}$ \\
6 & $5 \%$ tannic acid $+30 \%$ phosphoric acid & $5 \mathrm{~T}-30 \mathrm{P}$ \\
\hline
\end{tabular}

The elemental composition and valence state of elements were investigated by XPS (British VG's MCROLAB MK II $\mathrm{X}$-ray photoelectron spectroscopy). Magnesium was used as $\mathrm{X}$-ray photon source with a power of $160 \mathrm{~W}$. The energy analyser was set at $50 \mathrm{eV}$. The focusing voltage was $3 \mathrm{kV}$. An argon pressure of $1 \times 10^{-4} \mathrm{~Pa}$ and a vacuum pressure of $0.5 \times$ $10^{-6} \mathrm{~Pa}$ were used for sputtering. The angle between $\mathrm{Ar}^{+}$ions sputtering gun and sample surface was $45^{\circ}$. Scan started 5 min after $\mathrm{Ar}^{+}$ions sputtering.

\section{Results and Discussion}

3.1. Microstructures and Structures of FeOOH. FTIR spectra of the samples prepared in the present work showed typical features of $\alpha-, \beta-, \gamma$-, and $\delta$-FeOOH (Figure 2). The FTIR bands recorded at $1628 \mathrm{~cm}^{-1}$ were ascribed to the $-\mathrm{OH}$ stretching vibration, whereas the bands at 883 and $795 \mathrm{~cm}^{-1}$ were ascribed to the $-\mathrm{OH}$ bending modes in $\alpha-\mathrm{FeOOH}$ [23]; bands at 847 and $696 \mathrm{~cm}^{-1}$ were ascribed to the $-\mathrm{OH}$ bending modes in $\beta$-FeOOH [24]; nearby bands at 1020 and $750 \mathrm{~cm}^{-1}$ were the bending vibration of $-\mathrm{OH}$ modes in $\gamma$-FeOOH [12]; and bands at 1120 and $975 \mathrm{~cm}^{-1}$ were the bending vibration of $\mathrm{OH}$ modes in $\delta$-FeOOH [25]. The four types of FeOOH were also confirmed by XRD analyses (Figure 3 ). Under the TEM observation, the $\alpha$-FeOOH was granular, $\beta$-FeOOH appeared as rod-shaped, while $\gamma$-FeOOH looked like fine needles, and $\delta$-FeOOH was irregularly cotton-like (Figure 4$)$. Different types of corrosion products would cause different degrees of iron corrosion. As $\alpha$-FeOOH is relatively stable, it may attribute to nondetrimental rust. On the other hand, the clubshaped $\beta$-FeOOH and fine needle-like $\gamma$-FeOOH had loose texture that could store large amounts of moisture, resulting in more iron corrosion.

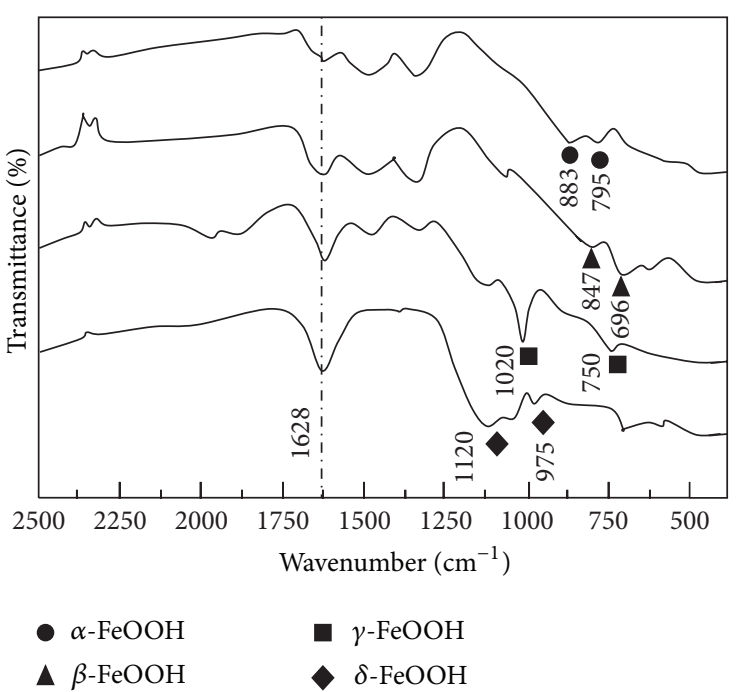

FIGURE 2: FTIR spectra of different forms of FeOOH. ๑: $\alpha$-FeOOH; $\Delta$ : $\beta$-FeOOH; $\backsim:$ - FeOOH; $\bullet: \delta$-FeOOH.

3.2. Influence of $\beta-\mathrm{FeOOH}$ and $\gamma-\mathrm{FeOOH}$ on Corrosion of Archaeological Iron. Corrosion morphologies of the surface between cast iron and $\beta-\mathrm{FeOOH}$ or $\gamma$-FeOOH under the action of different ions $\mathrm{NO}_{3}{ }^{-}, \mathrm{Cl}^{-}, \mathrm{HSO}_{4}{ }^{-}$, and $\mathrm{Cl}^{-}+\mathrm{HSO}_{4}{ }^{-}$ were illustrated in Figure 5. FeOOH was sandwiched in between epoxide resin on top and cast iron on bottom. The boundaries were marked with white lines to help delineate the rust surface.

The surface between $\gamma$-FeOOH and cast iron varied significantly with different types of ions. The surface was relatively flat when $\mathrm{NO}_{3}{ }^{-}$was used (Figure 5(a)). Similar to $\mathrm{NO}_{3}{ }^{-}$, a clear $\gamma$-FeOOH layer could be seen under the action of $\mathrm{Cl}^{-}$(Figure 5(c)). When $\mathrm{HSO}_{4}{ }^{-}$was added, the interface became fuzzy (Figure 5(e)), indicating that $\mathrm{HSO}_{4}{ }^{-}$could lead to more serious corrosion. The interface became more irregular under the influence of $\mathrm{Cl}^{-}+\mathrm{HSO}_{4}{ }^{-}$(Figure 5(g)). More corrosion of the cast iron was observed, when the freshly formed rust layer was connected to $\gamma$-FeOOH layer. In the presence of $\mathrm{Cl}^{-}$and $\mathrm{SO}_{4}{ }^{2-}$, green rust would form which had little protection on iron and was just an intermediate $\mathrm{Fe}(\mathrm{II})$ $\mathrm{Fe}(\mathrm{III})$ hydroxyl-salt via which ferrous hydroxide $\mathrm{Fe}(\mathrm{OH})_{2}$ usually oxidizes into different ferric oxyhydroxides [26].

The change in surface morphology of $\beta$-FeOOH was similar to that of $\gamma$-FeOOH. When $\mathrm{NO}_{3}{ }^{-}$was added, the surface was relatively flat (Figure 5(b)). The surface corrosion became more serious as the anion was changed from $\mathrm{Cl}^{-}$to $\mathrm{HSO}_{4}{ }^{-}$(Figures 5(d) and 5(f)). When $\mathrm{Cl}^{-}+\mathrm{HSO}_{4}{ }^{-}$was acting on $\beta$-FeOOH, corrosion of the interface was so serious that it connected to the original $\beta$-FeOOH layers (Figure $5(\mathrm{~h})$ ).

The above observations showed that when either $\gamma$ $\mathrm{FeOOH}$ or $\beta$-FeOOH adhered to iron surface, it was unable to prevent different anions from reaching the iron surface. In another word, the two hydroxy-oxide rust layers were not strong enough to provide a good protection and prevent iron from further corrosion. With relatively loose textures, $\gamma$ $\mathrm{FeOOH}$ and $\beta$-FeOOH not only failed to stop anions from 


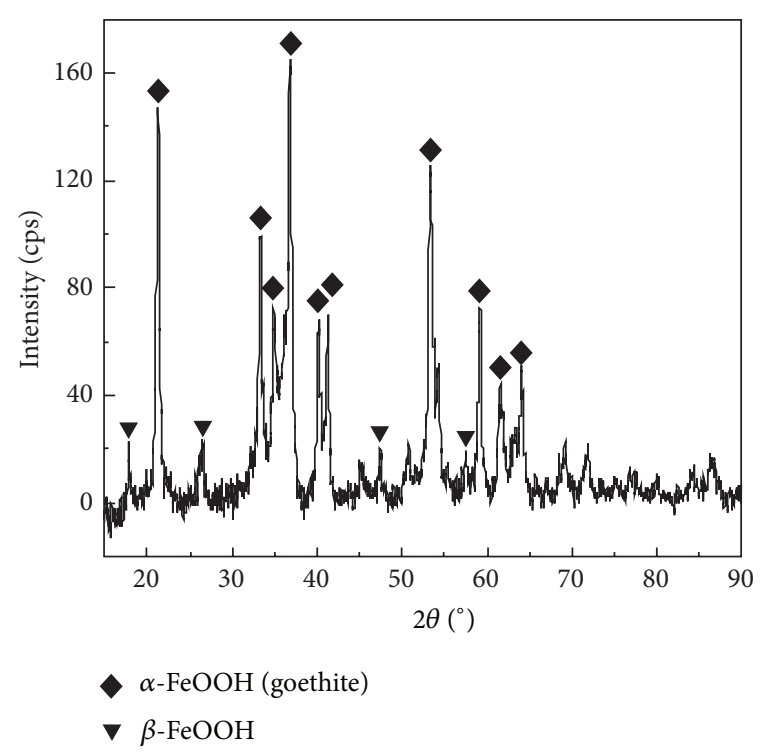

(a)

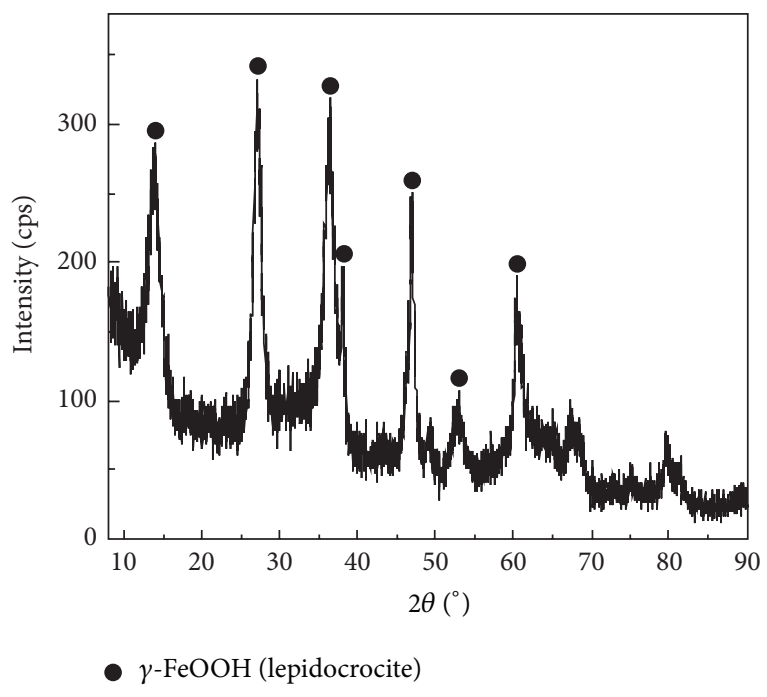

(c)

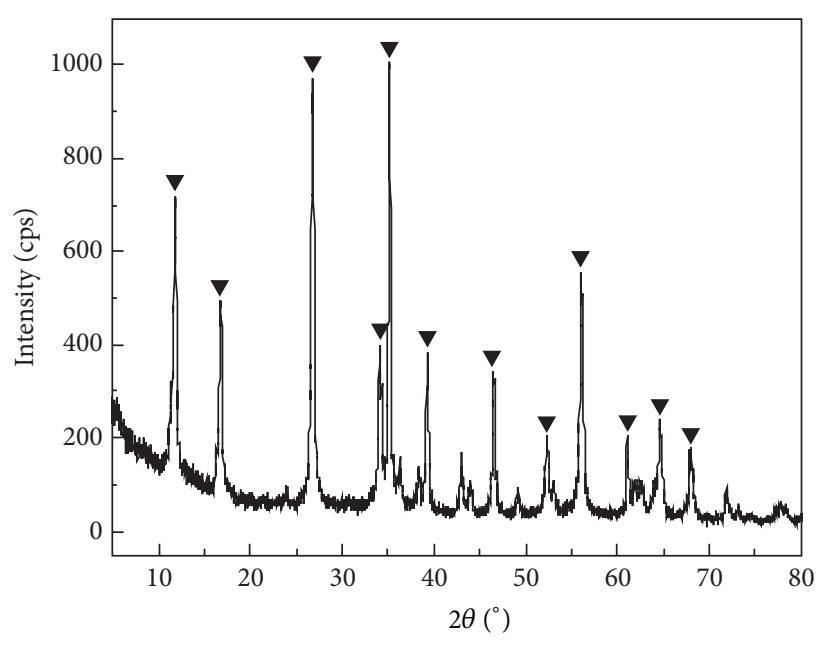

$\boldsymbol{\nabla} \beta-\mathrm{FeOOH}$ (akaganeite)

(b)

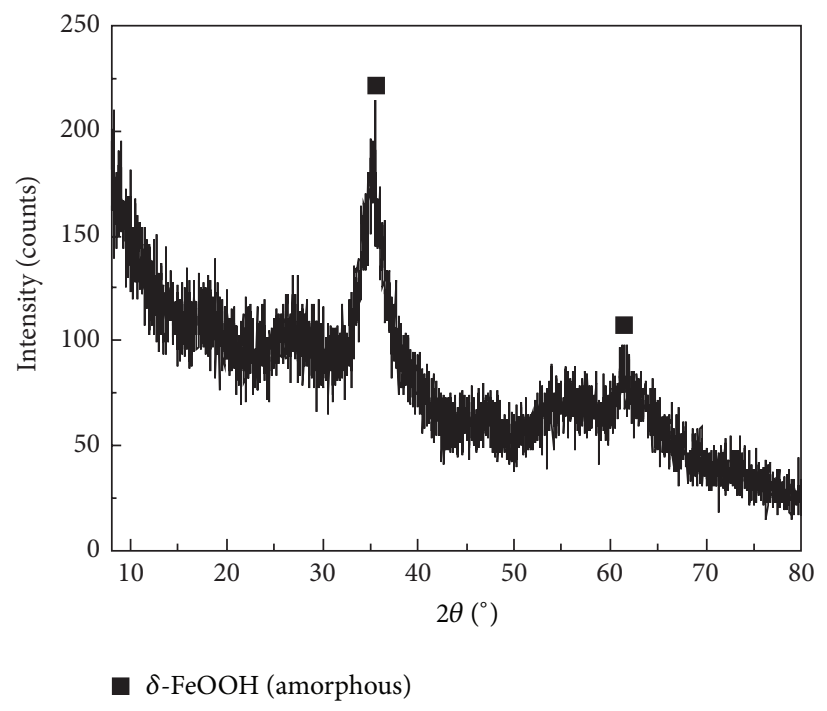

(d)

Figure 3: X-ray diffraction patterns of different forms of FeOOH. $\bullet$ - $\alpha$ FeOH; $\mathbf{\nabla}: \beta$-FeOOH; $\bullet: \gamma$-FeOOH; $\mathbf{\square}: \delta$-FeOOH.

corroding the iron, but also became a storage area for anions and moisture, resulting in strong adsorption. Meanwhile, it slowed down the evaporation rate of moisture and extended the corrosion cycle of moisture, thus promoting corrosive ions acting on the cast iron.

Moreover, among the common anions in atmosphere that would cause corrosion, $\mathrm{NO}_{3}{ }^{-}$had the weakest corrosion power on cast iron. The corrosive power increased progressively, following the order $\mathrm{Cl}^{-}+\mathrm{HSO}_{4}{ }^{-}>\mathrm{HSO}_{4}>\mathrm{Cl}^{-}$. Under the combined action of $\mathrm{Cl}^{-}$and $\mathrm{HSO}_{4}{ }^{-}$, the corrosion of cast iron was much more serious than any other ions used alone, indicating synergistic activities between $\mathrm{Cl}^{-}$and $\mathrm{HSO}_{4}{ }^{-} \cdot \beta-$ $\mathrm{FeOOH}$ was produced exclusively in the presence of $\mathrm{Cl}^{-}$[27] which had weaker iron protection and resulted in more iron rusting. The corrosion product of cast iron in contact with the $\mathrm{FeCl}_{2}$ solution over 138 days was made up of three layers: $\alpha$ - $\mathrm{FeOOH}, \mathrm{Fe}_{3} \mathrm{O}_{4}$, and a little $\beta$ - $\mathrm{FeOOH}$ in the inner layer, $\gamma$ $\mathrm{FeOOH}$ in the middle layer, and $\alpha-\mathrm{FeOOH}$ in the outer layer [28].

3.3. Interactions between $\mathrm{FeOOH}$ and Different Combinations of Phosphoric Acid/Tannic Acid. Different states and colors of reaction products after filtrating, drying, and grinding were documented in Table 2. The yellow powder and tannic acid were identical in material phases and composition, suggesting that the yellow powder was excess tannins. As tannic acid dissolves $\gamma$-FeOOH and higher concentrations of tannic acid speeded up the dissolution [29], it is suggested that $\mathrm{FeOOH}$ 


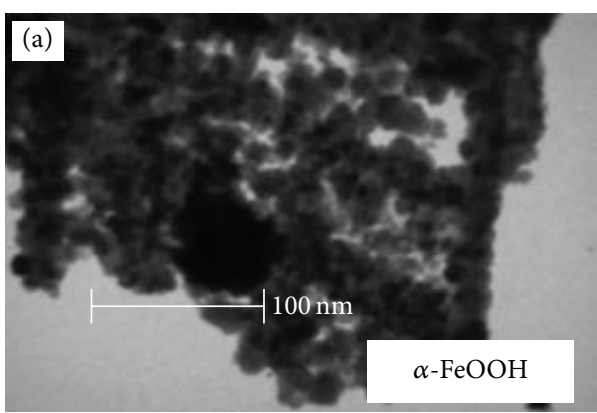

(a)

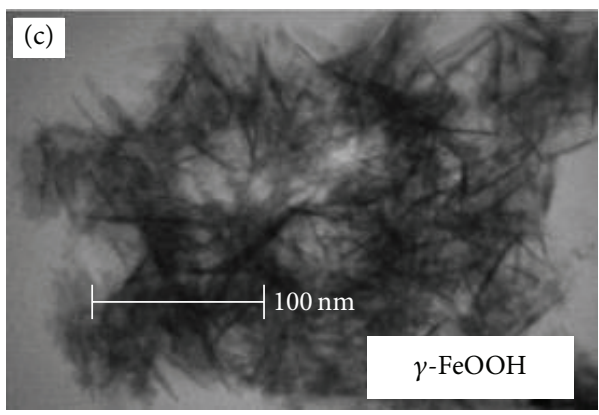

(c)

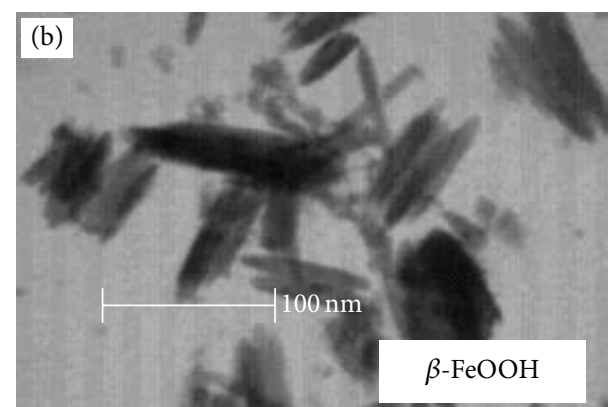

(b)

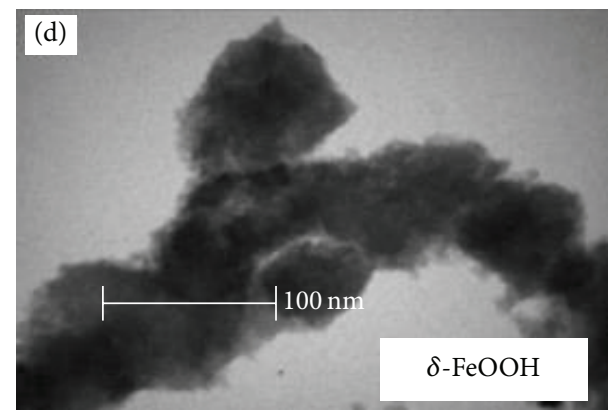

(d)

Figure 4: TEM images of different forms of $\mathrm{FeOOH}$.

TABLE 2: The state and color of reaction products.

\begin{tabular}{lccc}
\hline Phosphoric acid/tannic acid & $\beta$-FeOOH & $\gamma$-FeOOH & $\delta$-FeOOH \\
\hline 3T-10P & Gray powder & Gray powder & Gray powder \\
3T-20P & Gray powder & Yellow powder & Less product, blue-gray \\
3T-30P & Less product, beige & Yellow powder & Yellow powder \\
5T-10P & Gray powder & Blue-gray, yellow & Blue-gray powder \\
5T-20P & Gray powder & Yellow powder & Blue-gray powder \\
5T-30P & Less product, beige & Less product, blue-gray & Yellow powder \\
\hline
\end{tabular}

was completely dissolved. Thus, these proportions were not suitable as a choice of rust stabilizer formula, due to accumulation of residual tannic acid after reaction. In addition, for some combinations, the reaction products were very limited, indicating that most of the $\mathrm{FeOOH}$ was dissolved under the action of phosphoric acid/tannic acid. Only a small amount of $\mathrm{FeOOH}$ was involved in chemical transformation. Thus, these combinations were also undesirable for rust stabilizer formula.

At the same time, according to protection standards of cultural relics, protection materials must be close to original artifacts to the maximum extent. Among the combinations in Table 2, only the product of the 3T-10P, namely, 3\% tannic acid $+10 \%$ phosphoric acid and $\mathrm{FeOOH}$, was gray, similar to the color of steel materials, suggesting that $3 \%$ tannic acid $+10 \%$ phosphoric acid was the most suitable formula for rust stabilizer. Previous studies showed that conventional anticorrosive paints or the painting schemes applied on steel previously treated with a primer formulated with pine tannins extend the duration of painting schemes more than 50\% relative to the case without this chemical treatment [30].
The XRD pattern of reaction products of $\beta$-, $\gamma^{-}$, and $\delta$ FeOOH and 3T-10P was presented in Figure 6. A crystalline phosphate was the major product and it matched the XRD patterns of $\mathrm{Fe}_{3} \mathrm{P}_{6} \mathrm{O}_{2}$ well. In contrast, the major constituents of the scale on Delhi iron pillar were crystalline iron hydrogen phosphate hydrate $\left(\mathrm{FePO}_{4} \cdot \mathrm{H}_{3} \mathrm{PO}_{4} \cdot 4 \mathrm{H}_{2} \mathrm{O}\right)$ as well as $\alpha-, \gamma$, and $\delta$-FeOOH and magnetite [30] or crystalline phosphate $\mathrm{Fe}_{2}\left(\mathrm{PO}_{4}\right)(\mathrm{OH})$ [7]. No phases related to tannic acid were identified, suggesting that the transformation products of tannic acid and $\mathrm{FeOOH}$ were amorphous.

The transformation products from the reaction of tannic acid/phosphoric acid and $\mathrm{FeOOH}$ were further characterized by XPS. The reaction products between $\beta-\mathrm{FeOOH}$ and $3 \mathrm{~T}-$ $10 \mathrm{P}$ were mainly $\mathrm{Fe}, \mathrm{C}, \mathrm{P}$, and $\mathrm{O}$ (Figure 7 ). The binding energy of $\mathrm{Fe} 2 \mathrm{p}_{3 / 2}$ was $712.42 \mathrm{eV}$, confirming the presence of $\mathrm{Fe}^{3+}$ in the product. The binding energy of $\mathrm{Cls}$ can be decomposed to $285.07,286.89$, and $288.50 \mathrm{eV}$, with the former corresponding to carbon and the combination of the latter two corresponding to standard spectral peaks of carboxide in tannic acid. The binding energy of O1s was $531.95 \mathrm{eV}$, corresponding to $\mathrm{C}-\mathrm{OH}$ in tannic acid. In addition, the peak at $133.64 \mathrm{eV}$ was 


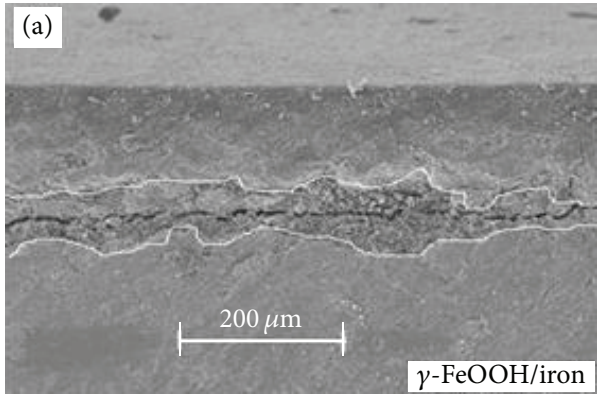

(a)

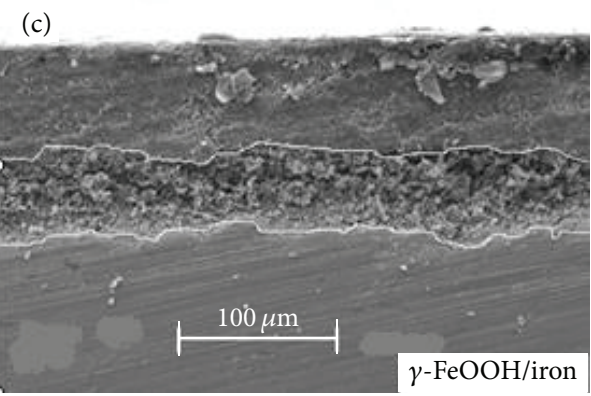

(c)

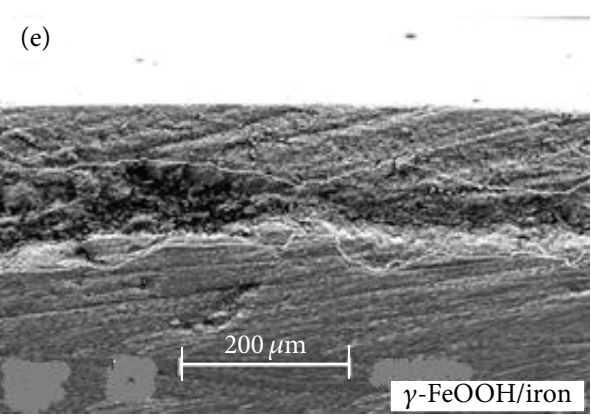

(e)

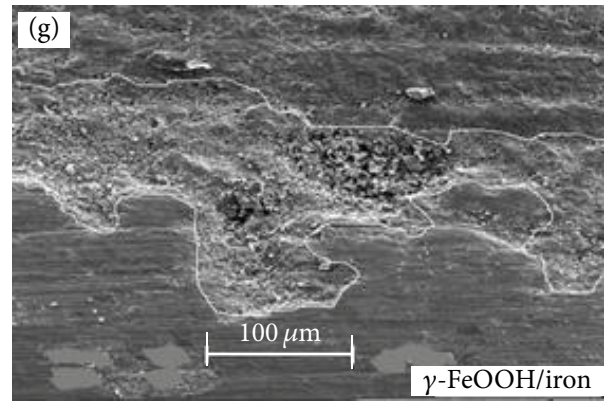

(g)

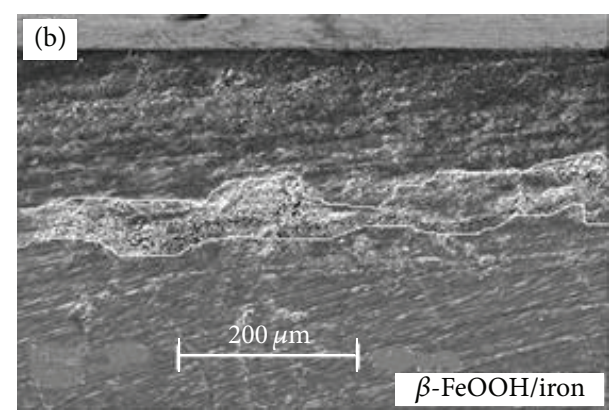

(b)

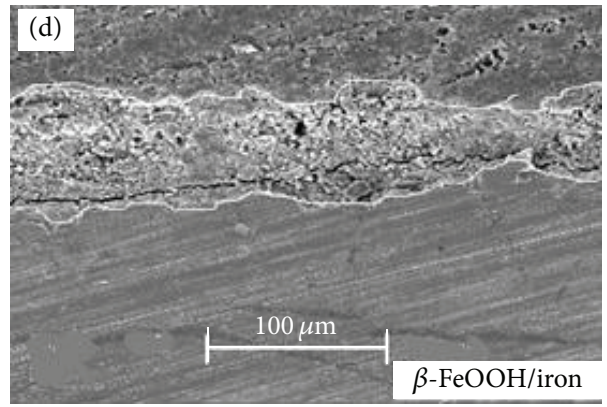

(d)

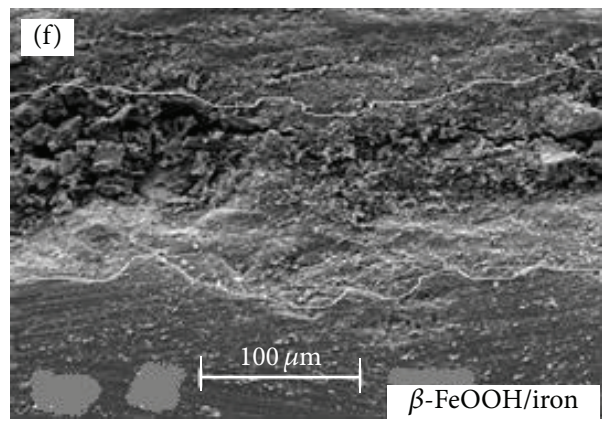

(f)

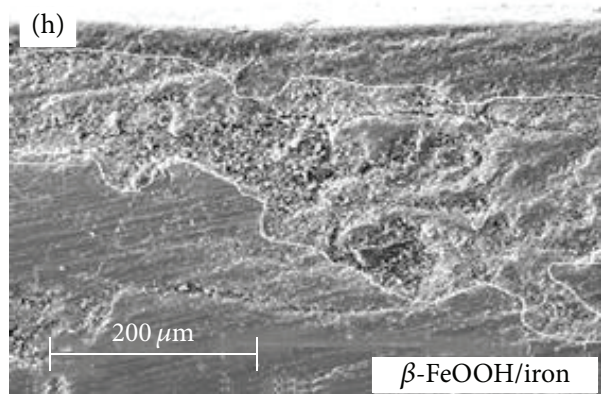

(h)

FIGURE 5: SEM images of rust powder/cast iron interface with the effects of $\mathrm{NO}_{3}{ }^{-}\left((\mathrm{a})\right.$ and (b)); $\mathrm{Cl}^{-}((\mathrm{c})$ and $(\mathrm{d}))$; $\mathrm{HSO}_{4}{ }^{-}((\mathrm{e})$ and (f)); and $\mathrm{Cl}^{-}+\mathrm{HSO}_{4}^{-}((\mathrm{g})$ and $(\mathrm{h}))$.

originated from P2p, confirming the presence of phosphate. The peaks of $\mathrm{Fe}_{2} \mathrm{p}_{3 / 2}$ in $\mathrm{Fe}^{3+}$ generally lie between 710.20 and $711.05 \mathrm{eV}$. However, the binding energy of $\mathrm{Fe} 2 \mathrm{p}_{3 / 2}$ in this study was $712.42 \mathrm{eV}$, resulting in a chemical shift of more than $1 \mathrm{eV}$. Such a shift may suggest a change in chemical environment of the elements, thus indicating formation of a new chemical bond between $\mathrm{Fe}^{3+}$ and other substances. Due to the presence of tannic acid, it may suggest the formation of chelate between iron and tannin [31] as illustrated in Scheme 1. 


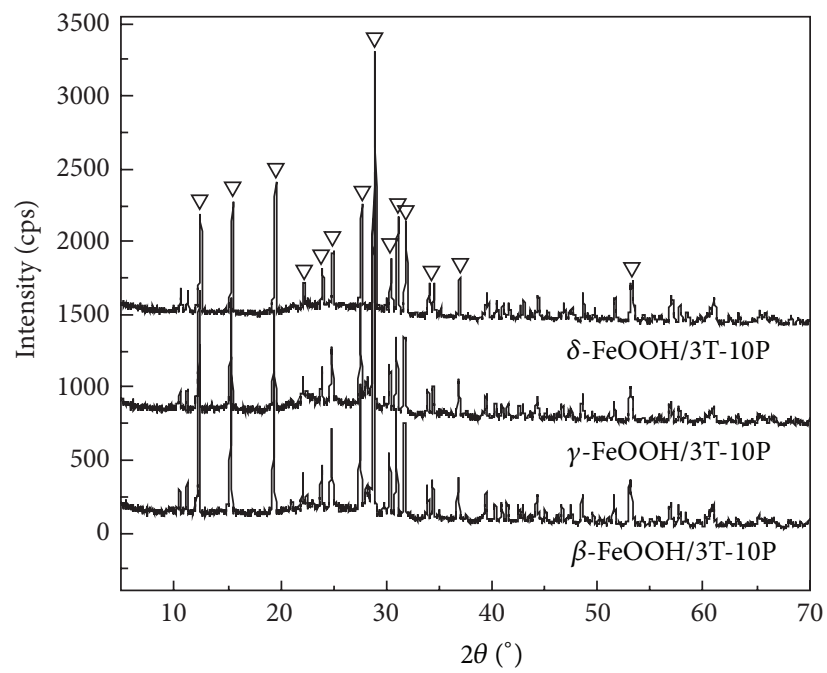

$\nabla \mathrm{Fe}_{3} \mathrm{P}_{6} \mathrm{O}_{2}$

FIGURE 6: XRD patterns of the products formed from the reaction of FeOOH and 3T-10P.

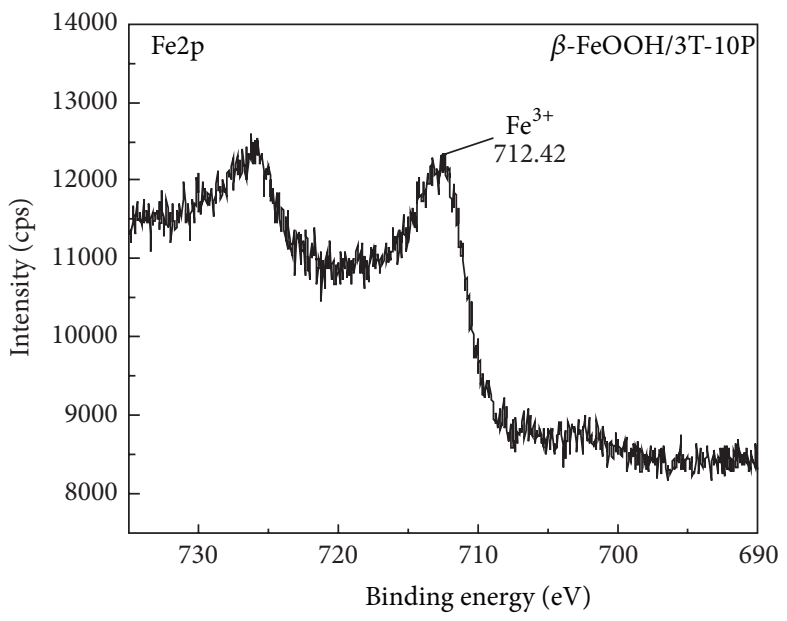

(a)

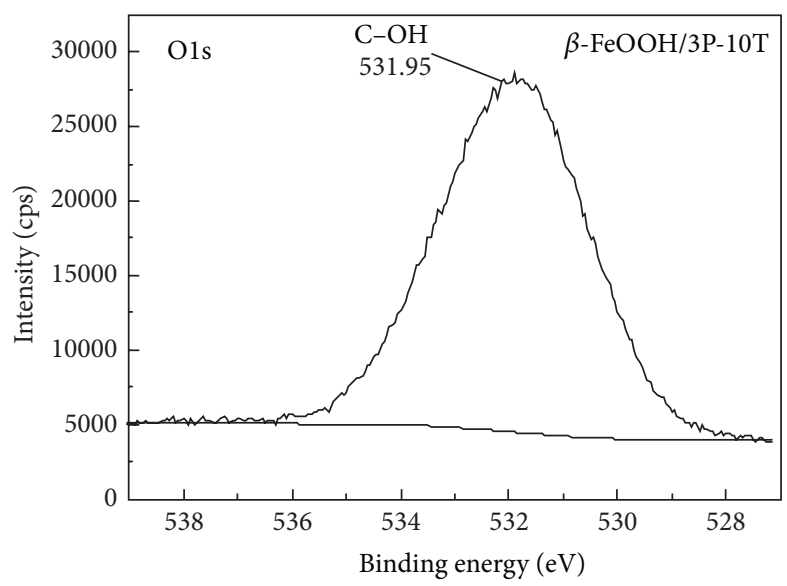

(c)

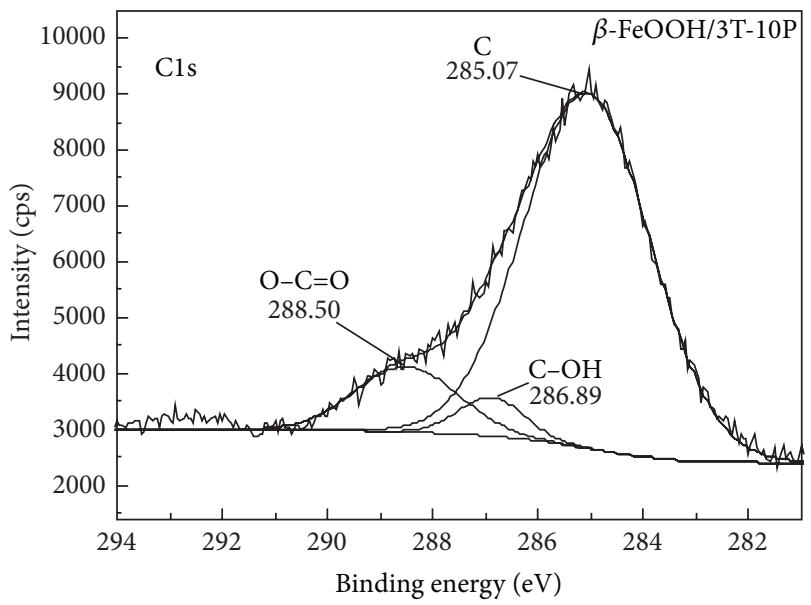

(b)

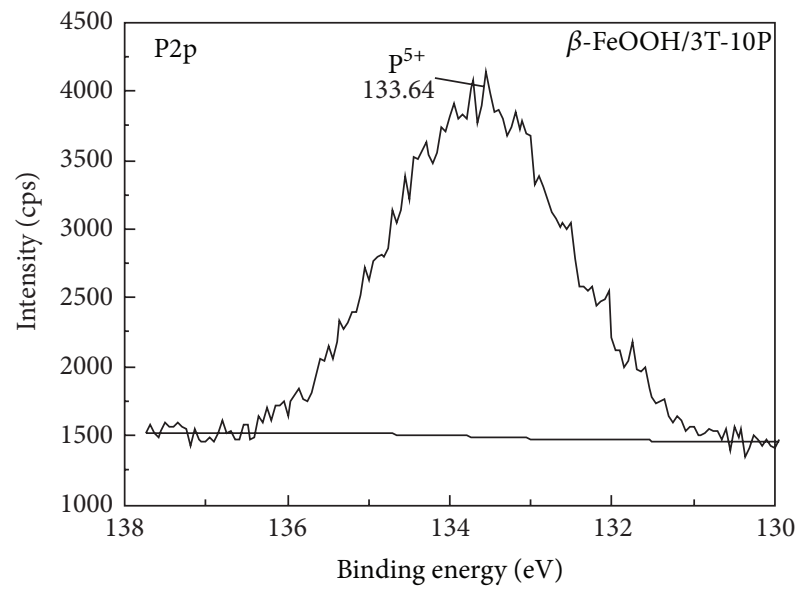

(d)

Figure 7: XPS spectra of the products formed from the reaction of $\beta$-FeOOH and 3T-10P. 


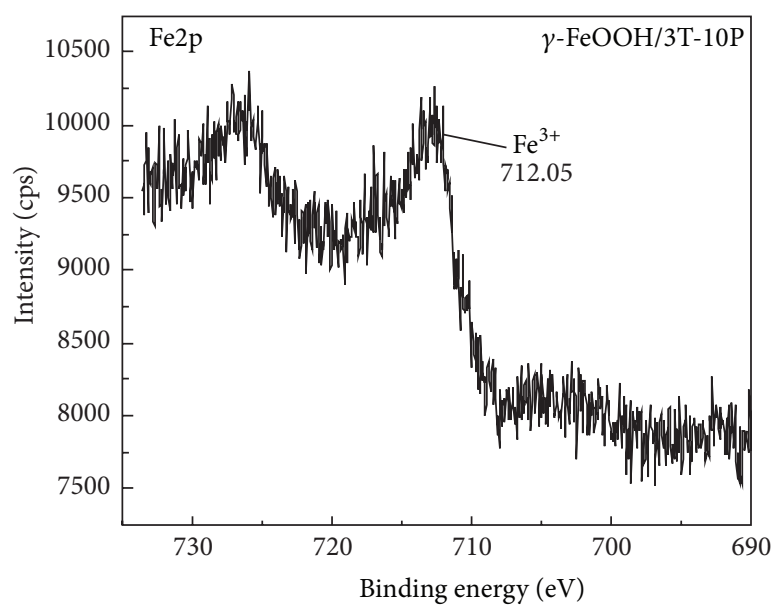

(a)

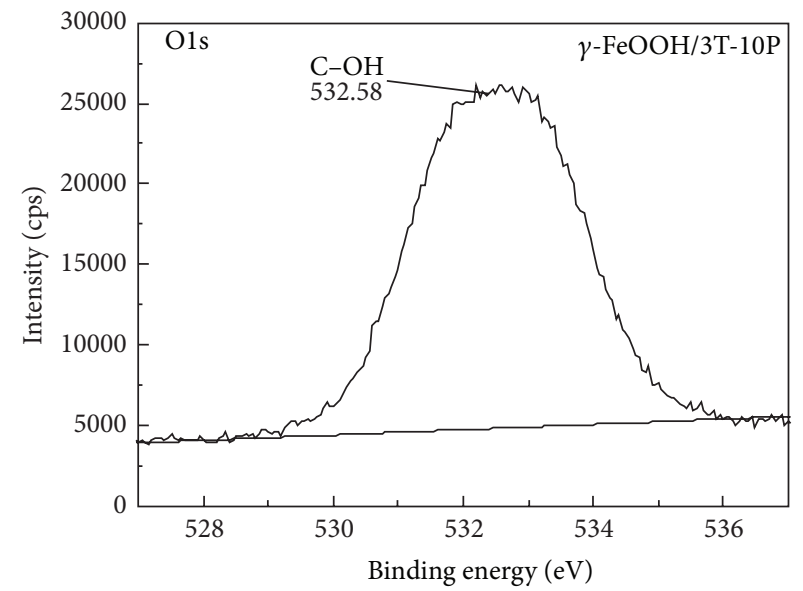

(c)

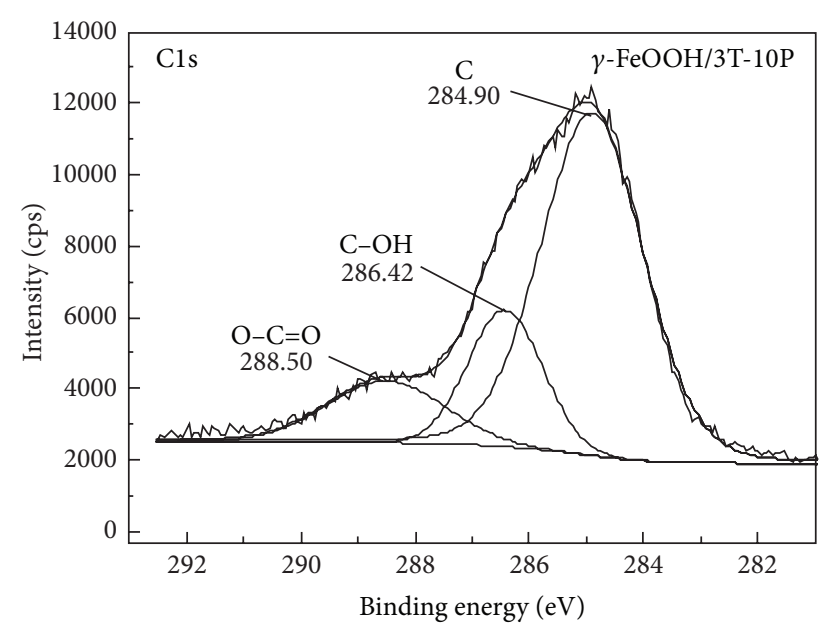

(b)

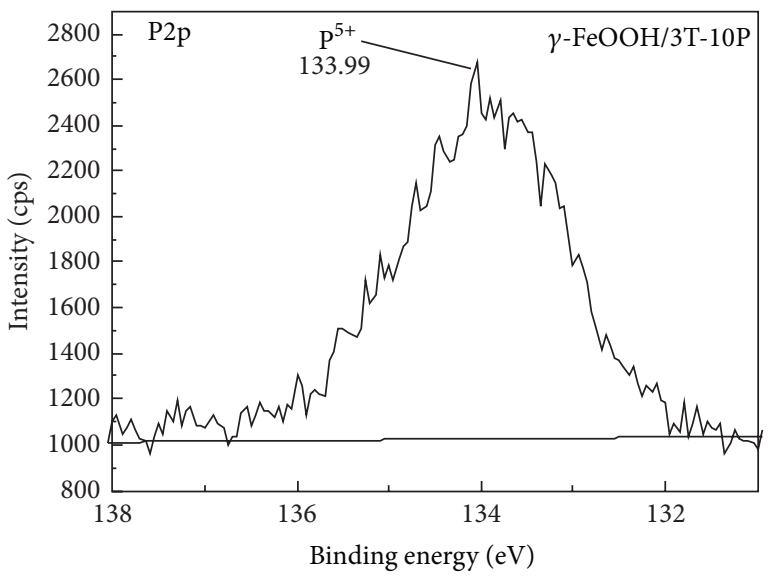

(d)

FIGURE 8: XPS spectra of the products formed from the reaction of $\gamma-\mathrm{FeOOH}$ and 3T-10P.<smiles>[R]c1cc(O)c(O)c(CC(C)C(C)C)c1</smiles>

Scheme 1: Single-chelate complex ion body.

Thus, it was speculated that the reaction products of $\beta$ $\mathrm{FeOOH}$ and 3T-10P were made up of iron phosphate and chelate of iron and tannin.

The results of XPS analyses of the reaction products generated by $\gamma$-FeOOH and 3T-10P and by $\delta$ - FeOOH and 3T$10 \mathrm{P}$ were illustrated in Figures 8 and 9. The composition of these two products was similar to the reaction products of $\beta$ $\mathrm{FeOOH}$ and 3T-10P, that is, was made mainly of Fe, C, P, and $\mathrm{O}$ and having about the same peak positions. Therefore, the reaction products were mainly made of iron phosphate and chelate of iron and tannin.
The structures of iron phosphate and chelate of iron and tannin are relatively stable. If acting as chemical conversion layer, the cast iron may develop strong corrosion resistance capacity. Meanwhile, the layer can enhance bonding between the coating and the substrate. These favorable physical and chemical properties could meet the need of coating and sealing treatment for iron artifact. However, the mechanisms of tannic acid/phosphoric acid rust conversion may need further study.

\section{Conclusions}

(1) When cast iron was covered by $\beta$-FeOOH and $\gamma$ $\mathrm{FeOOH}$ corrosion, the rust layer was porous and not tight enough to provide a good protection against corrosion by $\mathrm{NO}_{3}{ }^{-}, \mathrm{Cl}^{-}, \mathrm{HSO}_{4}^{-}$, and $\mathrm{Cl}^{-}+\mathrm{HSO}_{4}^{-}$.

(2) Among common anions tested, $\mathrm{NO}_{3}{ }^{-}$had the weakest corrosive power on cast iron. The corrosion power increased in the following sequence: $\mathrm{Cl}^{-}, \mathrm{HSO}_{4}{ }^{-}$, and $\mathrm{Cl}^{-}+\mathrm{HSO}_{4}^{-}$. Meanwhile, synergistic corrosion could be enhanced when both $\mathrm{Cl}^{-}$and $\mathrm{HSO}_{4}{ }^{-}$were present. 


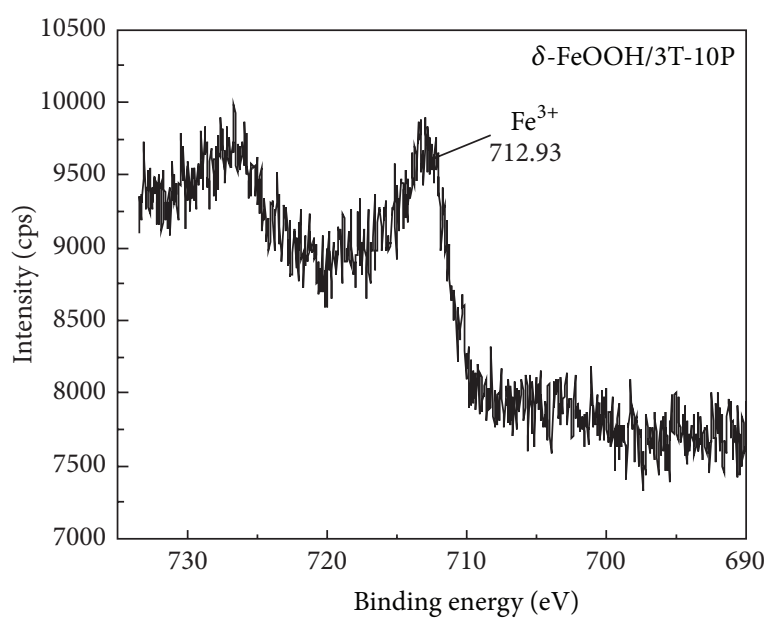

(a)

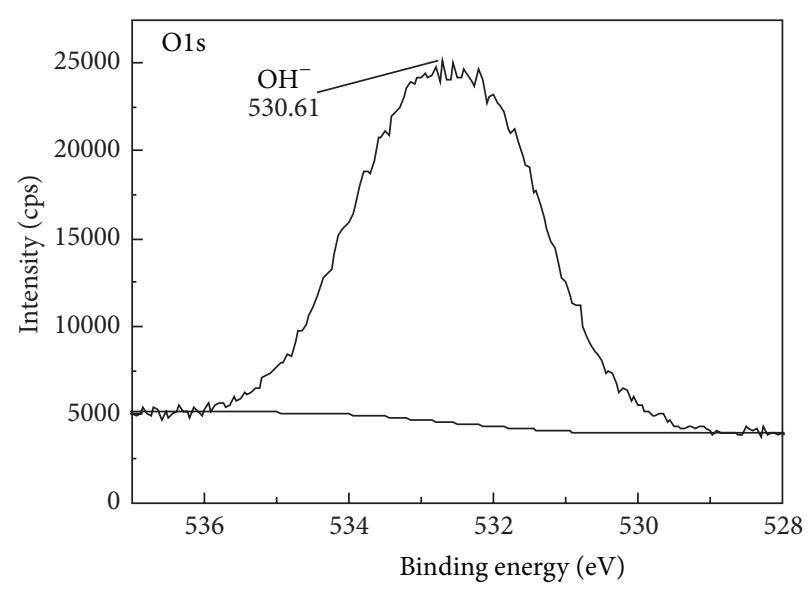

(c)

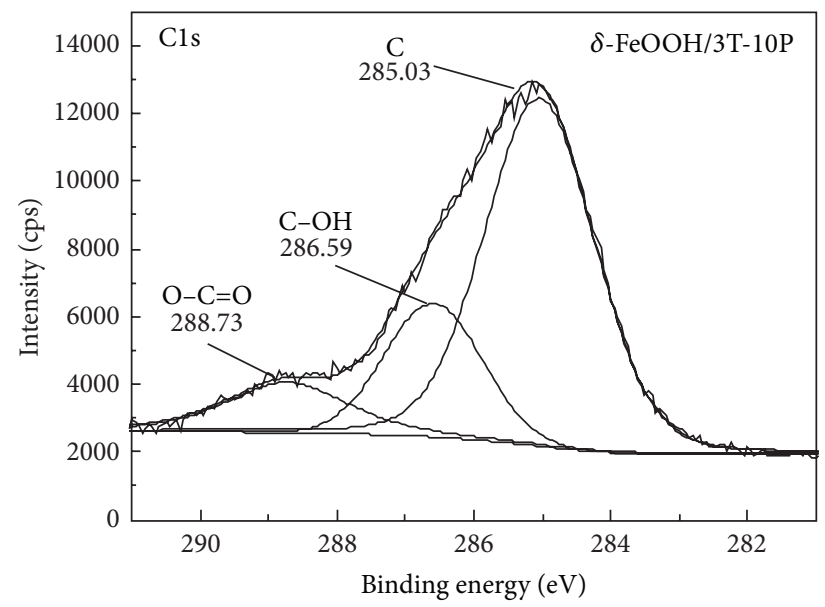

(b)

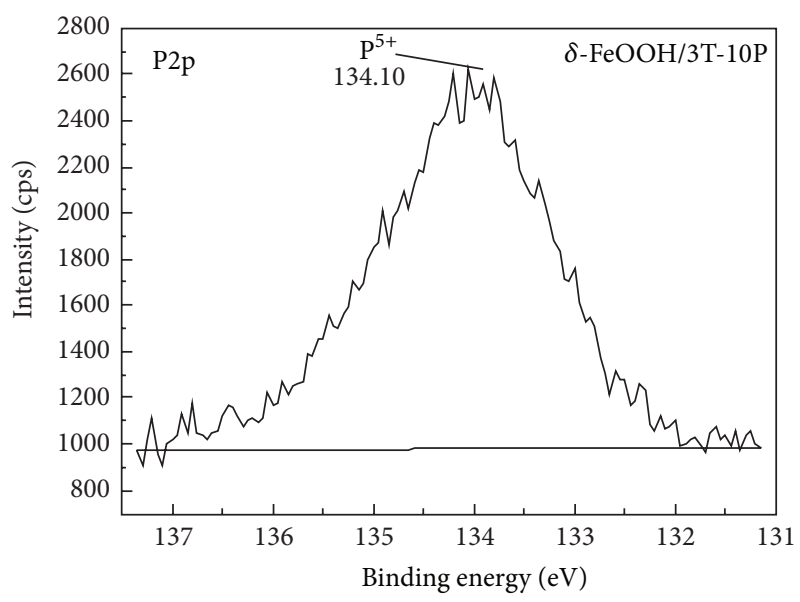

(d)

FIGURE 9: XPS spectra of the products formed from the reaction of $\delta$-FeOOH and 3T-10P.

(3) Analyses of the reaction products between $\mathrm{FeOOH}$ and different combinations of phosphoric acid/tannic acid showed that $3 \%$ tannic acid $+10 \%$ phosphoric acid was the most suitable formula as rust stabilizer.

(4) The reaction products between $\beta$ - $\mathrm{FeOOH}, \gamma$ - FeOOH, or $\delta$ - $\mathrm{FeOOH}$ and 3T-10P were made up of iron phosphate and chelate of iron and tannin.

\section{Conflict of Interests}

The authors declare that there is no conflict of interests regarding the publication of this paper.

\section{Acknowledgments}

This present work was supported by the National Natural Science Foundation of China (Grants nos. 51202226 and 51172216) and the Fundamental Research Funds for the Central Universities (Grant no. 2652013043).

\section{References}

[1] W. Xu, K. Daub, X. Zhang, J. J. Noel, D. W. Shoesmith, and J. C. Wren, "Oxide formation and conversion on carbon steel in mildly basic solutions," Electrochimica Acta, vol. 54, no. 24, pp. 5727-5738, 2009.

[2] X. Liu, G. Qiu, A. Yan, Z. Wang, and X. Li, "Hydrothermal synthesis and characterization of $\alpha-\mathrm{FeOOH}$ and $\alpha-\mathrm{Fe}_{2} \mathrm{O}_{3}$ uniform nanocrystallines," Journal of Alloys and Compounds, vol. 433, no. 1-2, pp. 216-220, 2007.

[3] H. Abdel-Samad and P. R. Watson, "An XPS study of the adsorption of lead on goethite $(\alpha-\mathrm{FeOOH})$, , Applied Surface Science, vol. 136, no. 1-2, pp. 46-54, 1998.

[4] C.-J. Jia, L.-D. Sun, Z.-G. Yan et al., "Single-crystalline iron oxide nanotubes," Angewandte Chemie, vol. 44, no. 28, pp. 4328-4333, 2005.

[5] M. Žic, M. Ristić, and S. Musić, "The effect of temperature on the crystallization of $\alpha-\mathrm{Fe}_{2} \mathrm{O}_{3}$ particles from dense $\beta$-FeOOH suspensions," Materials Chemistry and Physics, vol. 120, no. 1, pp. 160-166, 2010. 
[6] A. Jagminas, K. Mažeika, E. Juška, J. Reklaitis, and D. Baltrunas, "Electrochemical fabrication and characterization of lepidocrocite $(\gamma-\mathrm{FeOOH})$ nanowire arrays," Applied Surface Science, vol. 256, no. 12, pp. 3993-3996, 2010.

[7] P. Dillmann, R. Balasubramaniam, and G. Beranger, "Characterization of protective rust on ancient Indian iron using microprobe analyses," Corrosion Science, vol. 44, no. 10, pp. 2231-2242, 2002.

[8] H. Tanaka, J. Wakatsuki, K. Kandori, T. Ishikawa, and T. Nakayama, "Role of zinc compounds on the formation, morphology, and adsorption characteristics of $\beta$-FeOOH rusts," Corrosion Science, vol. 52, no. 9, pp. 2973-2978, 2010.

[9] T. Ishikawa, M. Kumagai, A. Yasukawa, K. Kandori, T. Nakayama, and F. Yuse, "Influences of metal ions on the formation of $\gamma$-FeOOH and magnetite rusts," Corrosion Science, vol. 44, no. 5, pp. 1073-1086, 2002.

[10] A. Collazo, X. R. Nóvoa, C. Pérez, and B. Puga, “The corrosion protection mechanism of rust converters: an electrochemical impedance spectroscopy study," Electrochimica Acta, vol. 55, no. 21, pp. 6156-6162, 2010.

[11] M. Žic, M. Ristić, and S. Musić, "Precipitation of $\alpha-\mathrm{Fe}_{2} \mathrm{O}_{3}$ from dense $\beta$-FeOOH suspensions with added ammonium amidosulfonate," Journal of Molecular Structure, vol. 924-926, pp. 235-242, 2009.

[12] C. Q. Cheng, J. Zhao, T. S. Cao, Q. Q. Fu, M. K. Lei, and D. W. Deng, "Facile chromaticity approach for the inspection of passive films on austenitic stainless steel," Corrosion Science, vol. 70, pp. 235-242, 2013.

[13] A. I. Muñoz, J. G. Antón, J. L. Guiñón, and V. P. Herranz, "Inhibition effect of chromate on the passivation and pitting corrosion of a duplex stainless steel in $\mathrm{LiBr}$ solutions using electrochemical techniques," Corrosion Science, vol. 49, no. 8, pp. 3200-3225, 2007.

[14] S. Powell, "Evaluation of alternative corrosion inhibitors to chromate for use in organic coatings using scanning reference electrode technique," Surface Engineering, vol. 16, no. 2, pp. 169$175,2000$.

[15] B. J. Basu, A. Srinivasan, J. Manasa, and V. K. W. Grips, "Improved corrosion protection of aluminium alloy AA 2024 by sol-gel hybrid coatings after surface pretreatment by silanisation," Surface Engineering, vol. 28, no. 4, pp. 294-299, 2012.

[16] Z. Liu, D. Yan, Y. Dong, Y. Yang, Z. Chu, and Z. Zhang, "The effect of modified epoxy sealing on the electrochemical corrosion behaviour of reactive plasma-sprayed TiN coatings," Corrosion Science, vol. 75, pp. 220-227, 2013.

[17] A. M. Simões, J. Torres, R. Picciochi, and J. C. S. Fernandes, "Corrosion inhibition at galvanized steel cut edges by phosphate pigments," Electrochimica Acta, vol. 54, no. 15, pp. 3857-3865, 2009.

[18] B. Gruss, "Iron phosphating," Metal Finishing, vol. 108, no. 11-12, pp. 33-37, 2010.

[19] D. Singh and S. Yadav, "Role of tannic acid based rust converter on formation of passive film on zinc rich coating exposed in simulated concrete pore solution," Surface and Coatings Technology, vol. 202, no. 8, pp. 1526-1542, 2008.

[20] B. Qian, B. Hou, and M. Zheng, "The inhibition effect of tannic acid on mild steel corrosion in seawater wet/dry cyclic conditions," Corrosion Science, vol. 72, pp. 1-9, 2013.

[21] A. Ostovari, S. M. Hoseinieh, M. Peikari, S. R. Shadizadeh, and S. J. Hashemi, "Corrosion inhibition of mild steel in 1 $\mathrm{M} \mathrm{HCl}$ solution by henna extract: a comparative study of the inhibition by henna and its constituents (Lawsone, Gallic acid, $\alpha$-d-Glucose and Tannic acid)," Corrosion Science, vol. 51, no. 9, pp. 1935-1949, 2009.

[22] K. W. Tan, M. J. Kassim, and C. W. Oo, "Possible improvement of catechin as corrosion inhibitor in acidic medium," Corrosion Science, vol. 65, pp. 152-162, 2012.

[23] B. Yuan, J. Xu, X. Li, and M.-L. Fu, "Preparation of Si-Al/ $\alpha$ $\mathrm{FeOOH}$ catalyst from an iron-containing waste and surfacecatalytic oxidation of methylene blue at neutral $\mathrm{pH}$ value in the presence of $\mathrm{H}_{2} \mathrm{O}_{2}$," Chemical Engineering Journal, vol. 226, pp. 181-188, 2013.

[24] S. Bashir, R. W. McCabe, C. Boxall, M. S. Leaver, and D. Mobbs, "Synthesis of $\alpha$ - and $\beta$-FeOOH iron oxide nanoparticles in nonionic surfactant medium," Journal of Nanoparticle Research, vol. 11, no. 3, pp. 701-706, 2009.

[25] L. Carlson and U. Schwertmann, "Natural occurrence of feroxyhite ( $\delta^{\prime}$-FeOOH)," Clays \& Clay Minerals, vol. 28, no. 4, pp. 272-280, 1980

[26] Z. Wang, C. Xu, and X. Dong, "Localized corrosion and phase transformation of simulated archaeological iron," Chinese Journal of Chemical Engineering, vol. 16, no. 2, pp. 299-305, 2008.

[27] C. Rémazeilles and P. Refait, "On the formation of $\beta-\mathrm{FeOOH}$ (akaganéite) in chloride-containing environments," Corrosion Science, vol. 49, no. 2, pp. 844-857, 2007.

[28] Z. Wang, C. Xu, X. Cao, and B. Xu, “The Morphology, phase composition and effect of corrosion product on simulated archaeological iron," Chinese Journal of Chemical Engineering, vol. 15, no. 3, pp. 433-438, 2007.

[29] S. Nasrazadani, “The application of infrared spectroscopy to a study of phosphoric and tannic acids interactions with magnetite $\left(\mathrm{Fe}_{3} \mathrm{O}_{4}\right)$, goethite $(\alpha-\mathrm{FeOOH})$ and lepidocrocite $(\gamma$ FeOOH)," Corrosion Science, vol. 39, no. 10-11, pp. 1845-1859, 1997.

[30] R. Balasubramaniam, "On the corrosion resistance of the Delhi iron pillar," Corrosion Science, vol. 42, no. 12, pp. 2103-2129, 2000.

[31] A. M. Al-Mayouf, "Inhibitors for chemical cleaning of iron with tannic acid," Desalination, vol. 121, no. 2, pp. 173-182, 1999. 

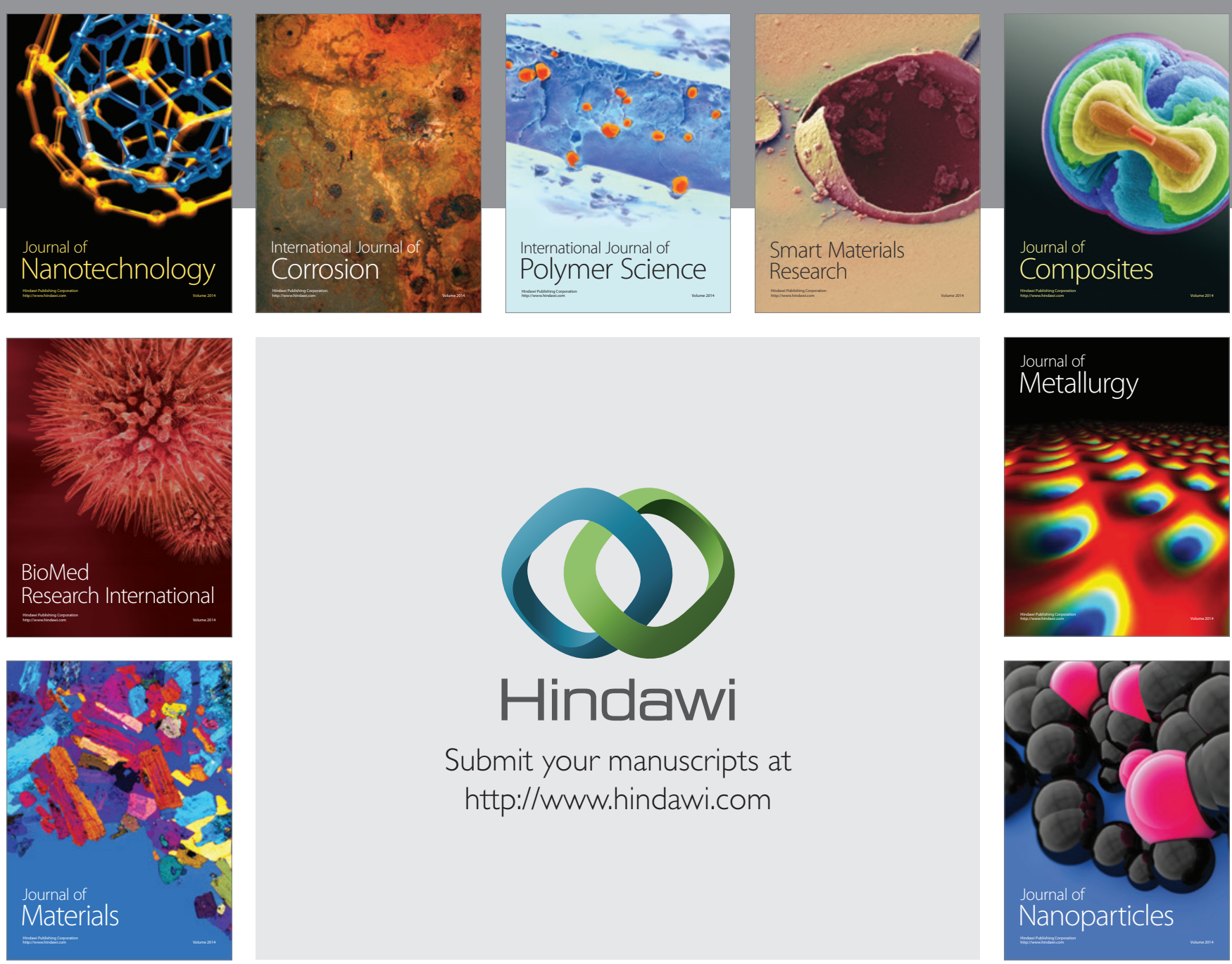

Submit your manuscripts at http://www.hindawi.com
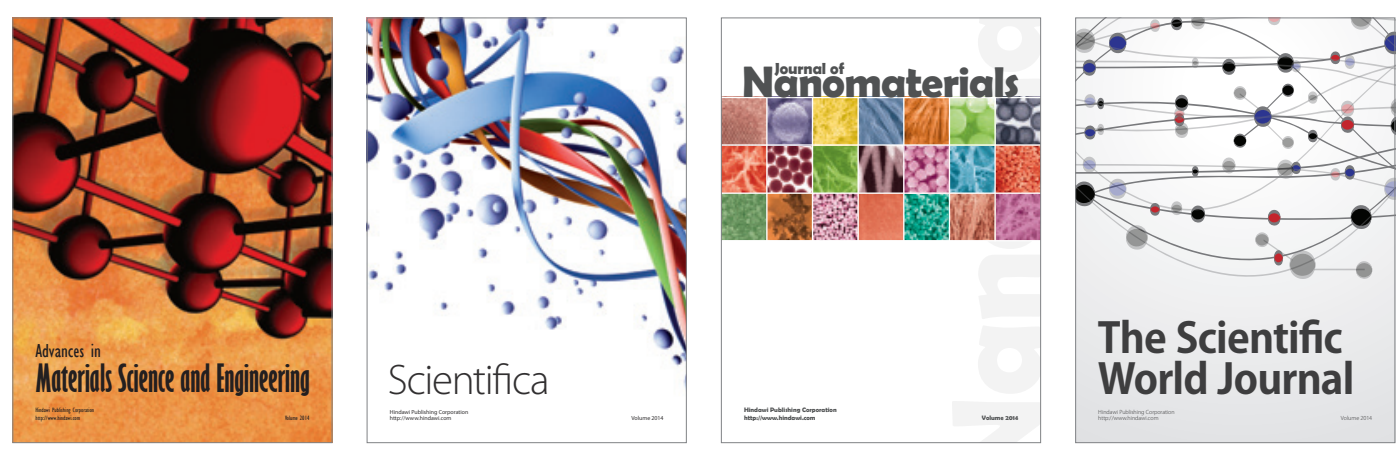

\section{The Scientific World Journal}
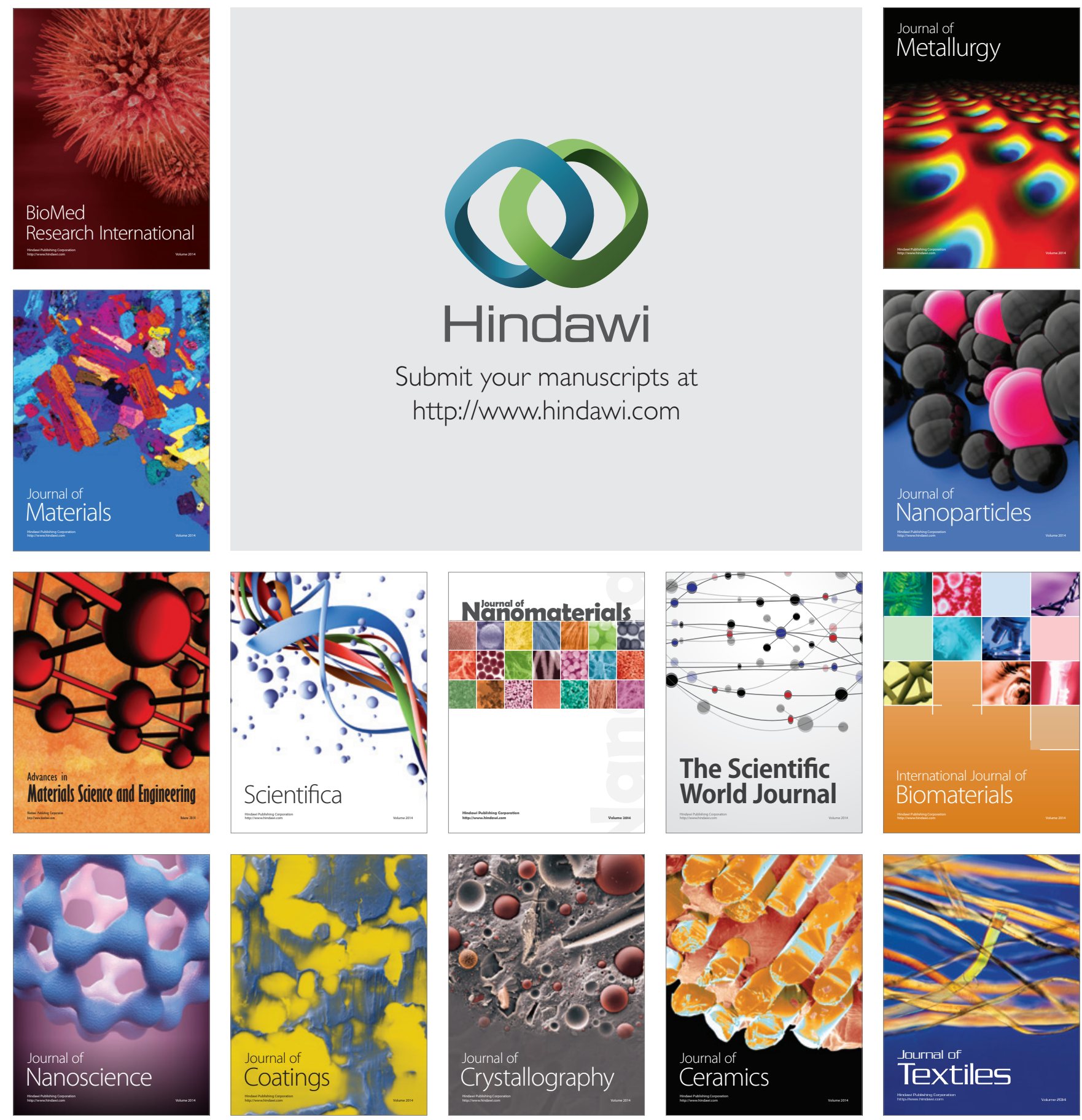